\title{
LATIHAN RANGE OF MOTION TERHADAP RENTANG GERAK SENDI EKSTREMITAS ATAS PASIEN STROKE DI RSUD M.NATSIR
}

\author{
Tintin Sumarni ${ }^{1}$; Yulastri ${ }^{2}$ \\ Politeknik Kesehatan Kemenkes Padang
}

\begin{abstract}
Stroke patients who experience hemiparese who do not receive proper treatment can cause complications of functional disorders, impaired mobilization, disruption of daily activities and incurable disabilities. The purpose of this study was to determine the effect of passive Range Of Motion (ROM) exercise on increasing the range of motion of stroke patients in the Neurology Room at RSUD M.Natsir. This research design is quasi experimental with the design used is one group pretest - postest design.In this study, passive Range Of Motion (ROM) was performed on the upper extremities of stroke patients for five days, twice a day. The number of respondents in 30 stroke patients who experienced hemiparese, The data was collected by direct measurement using a measuring instrument for the degree of motion of the joints, namely the goniometer, and data analysis was carried out using the $t$ dependent test (normally distributed data). The results showed a significant difference in the range of motion of the upper limb joints before and after passive ROM exercises. The conclusion that ROM exercises affect the range of motion of the upper limb joints in stroke patients. Passive ROM can be an alternative to increase the range of motion of the joints in the upper and lower extremities in stroke patients.
\end{abstract}

Keywords: Stroke; Weakness of movement; Range Of Motion Exercises

\begin{abstract}
Abstrak
Prevalensi stroke secara Nasional berdasarkan Riskesdas 2018 Provinsi Sumatera Barat berada di posisi 14 dari 34 provinsi yang ada di Indonesia, Kejadian stroke di RSUD M.Natsir merupakan urutan sepuluh penyakit terbanyak, tahun 2017 dirawat 207 orang dan 2018 menjadi 122 orang. Pasien stroke yang mengalami hemiparese yang tidak mendapat penanganan yang tepat dapat menimbulkan komplikasi gangguan fungsional, gangguan mobilisasi, gangguan aktifitas sehari-hari dan cacat yang tidak dapat disembihkan. Tujuan penelitian ini adalah untuk mengetahui pengaruh latihan Range Of Motion (ROM) pasif terhadap peningkatan rentang gerak sendi pasien stroke di Di Ruangan Neurologi RSUD M.Natsir. Desain penelitian ini quasi eksperimental dengan rancangan one group pretest postest design. Pada penelitian ini dilakukan Range Of Motion (ROM) pasif pada ekstremitas atas pasien stroke selama lima hari, dilakukan dua kali sehari. Jumlah responden pada 30 pasien stroke yang mengalami hemiparese, pengumpulan data dengan cara pengukuran langsung menggunakan alat ukur goniometer, analisis data dengan uji $t$ dependent didatkan hasil ada pengaruh rentang gerak sendi ekstremitas atas sebelum dan sesudah latihan $R O M$ pasif. nilai $p=0,000$. Kesimpulan latihan $R O M$ yang dilakukan secara teratur akan memperbaiki rentang gerak sendi ekstremitas atas pasien stroke, Diharapkan Pada perawat untuk memotivasi pasien dan keluaerga agar terus melakukan latihan range of motion secara rutin agar bagian tubuh yang mengalami kelemahan tidak berakibat pada atropi otot maupun kelumpuhan.
\end{abstract}

Kata kunci : Stroke; Kelemahan gerak; Latihan Range Of Motion 


\section{PENDAHULUAN}

Stroke adalah kehilangan fungsi otak yang diakibatkan oleh berhentinya suplai darah ke bagian otak. Sering ini adalah kulminasi penyakit serebrovaskular selama beberapa tahun Stroke mempunyai manifestasi klinis yang umum terjadi pada penderita stroke yaitu kehilangan motorik, kehilangan komunikasi, gangguan persepsi, kerusakan fungsi kognitif dan efek psikologik dan disfungsi kandung kemih ${ }^{1}$. Secara global, stroke menduduki urutan ketiga sebagai penyakit mematikan selain jantung dan kanker.sebagian besar stroke menyerang diatas usia 40 tahun, namun tidak bisa dipungkiri penyakit ini dapat juga menyerang semua usia ${ }^{2}$.

Prevalensi stroke di Indonesia berdasarkan diagnosis nakes tahun 2013 yaitu sebesar 7 $\%$ dan prevalensi stroke di Indonesia berdasarkan diagnosis dokter tahun 2018 yaitu 10,9 $\%$.Artinya dalam waktu kurun 5 tahun ini terjadi peningkatan penderita stroke di Indonesia sebesar 3.9\% ${ }^{4}$. Prevalensi stroke secara Nasional berdasarkan Riskesdas 2018 Provinsi Sumatera Barat berada di posisi 14 dari 34 provinsi yang ada di Indonesia ${ }^{4}$. Pasien pasca stroke pada umumnya mengalami kelemahan otot pada bagian anggota gerak tubuh, gangguan postural dan adanya atropi otot ${ }^{5}$. Atrofi otot menyebabkan penurunan aktivitas pada sendi sehingga sendi mengalami kehilangan cairan sinovial dan menyebabkan kekakuan sendi.Kekakuan sendi menyebabkan penurunan rentang gerak pada ${ }^{5}$.

Kelemahan sebagian esktremitas terjadi karena sebagian ekstremitas terjadi karena kerusakan area motorik korteks serebral yang mempersarafi ekstremitas. Kerusakan pada otak kanan menyebabkan kelemahan pada ekstremitas sebelah kiri. Sebaliknya kerusakan pada otak kiri menyebabkan kelemahan pada ektremitas sebelah kanan ${ }^{6}$. Rehabiltasi yang dapat diberikan untuk mengurangi dampak tersebut yaitu dengan pemberian terapi latihan berupa gerakan pasif sangat bermanfaat dalam menjaga sifat fisiologis dari jaringan otot dan sendi.

Prevalensi stroke secara Nasional berdasarkan Riskesdas 2018 Provinsi Sumatera Barat berada di posisi 14 dari 34 provinsi yang ada di Indonesia. Kejadian stroke di RSUD M.Natsir merupakan urutan sepuluh penyakit terbanyak, tahun 2017 dirawat 207 orang dan 2018 menjadi 122 orang. dan penatalaksanaannya telah melibatkan multi disiplin ilmu termasuk fisiotherapi, namun masih ditemukan ketidak patuhan dalam latihan, kurang motivasi dari pasien dan bantuan keluarga juga belum maksimal, sehingga pasien masih ada yang mengalami komplikasi selama dirawat dirumah.

Latihan Range of Motion (ROM) merupakan salah satu bentuk latihan dalam proses rehabilitasi yang dinilai masih cukup efektif untuk mencegah terjadinya kecacatan pada pasien dengan stroke. Latihan ini adalah salah satu bentuk intervensi fundamental perawat yang dapat dilakukan untuk keberhasilan regimen terapeutik bagi pasien dan dalam upaya pencegahan terjadinya kondisi cacat permanen pada pasien paska perawatan di rumah 
sakit sehingga dapat menurunkan tingkat ketergantungan pasien pada keluarga ${ }^{3}$. Tujuan kegiatan ini untuk mengetahui Perbedaan rentang gerak sendi ektremitas atas sebelum dan sesudah diberikan Latihan ROM Pasif kepada pasien Stroke di Ruang Neurologi RSUD M. Natsir Tahun 2020.

\section{METODE PENELITIAN}

Penelitian ini menggunakan penelitian quasi eksperimental dengan rancangan yang digunakan adalah one group pretest - postest design. Di dalam desain ini, pengukuran dilakukan sebanyak dua kali, yaitu pengukuran lingkup gerak sendi sebelum diberikan latihan ROM pasif (O1), kemudian diberikan ROM pasif $(\mathrm{X})$ dan pengukuran kekuatan lingkup gerak sendi setelah diberikan latihan ROM pasif (O2).Populasi dalam penelitian ini adalah seluruh penderita Stroke ruang Neurologi RSUD M.Natsir Kota Solok. sampel dengan menggunakan tehnik purposive samplingJumlah populasi pasien stroke (30 orang).

Data dikumpulkan oleh peneliti dengan mengukur rentang gerak sendi ekstremitas atas sebanyak dua kali, yaitu Sebelum diberikan intervensi dan setelah diberikan intervensi Latihan Range of Motion dilakukan selama 5 hari dilakukan 2 kali sehari. Instrumen yang digunakan pada pengumpulan data adalah pengukuran langsung menggunakan alat ukur derajat rentang gerak sendi yaitu goniometer, hasil pengukuran di catat menggunakan lembar observasi. Pengukuran dilakukan dengan teknik yang sama yaitu menggunakan alat ukur derajat rentang gerak sendi yaitu goniometer, di catat pada lembar observasi yang sama, dan pada pasien yang sama. . Latihan Range of Motion dilakukan selama 5 hari dengan pengulangan minimal 2 kali Analisis menggunakan uji parired sample t test. sehari.

\section{HASIL PENELITIAN}

$\begin{gathered}\text { Tabel 1.Distribusi Frekuensi Responden Berdasarkan Umur di Ruangan Neurologi } \\
\text { RSUD M. Natsir Kota Solok }(\mathbf{N}=\mathbf{3 0})\end{gathered}$
\begin{tabular}{cccc} 
Umur & Frequency & Percent \\
\hline $36-45$ & 4 & 13.3 \\
$46-55$ & 13 & 43.4 \\
$56-65$ & 10 & 33.3 \\
$>\quad 65$ & 3 & 10.0 \\
\hline Jenis Kelamin & & \\
$-\quad$ Laki-Laki & 16 & 53,3 \\
$-\quad$ Perempuan & 14 & 46,7 \\
\hline Pendidikan & & \\
- & SMP & 2 & 6.7 \\
- & SMA & 24 & 80.0 \\
- & PT & 4 & 13.3 \\
\hline
\end{tabular}

Pada table 1 menunjukkan hampir sebagian (43,4\%) responden berumur 46-55 tahun, dan lebih sebagian $(53,3 \%)$ berjeniskelamin laki-laki dan sebagian besar (80\%) berlatar belakang pendidikan sekolah menengah atas. 


\begin{tabular}{|c|c|c|c|c|}
\hline Variabel & Mean & Median & SD & Min-Max \\
\hline $\begin{array}{l}\text { Nilai Rentang Gerak } \\
\text { Sendi sebelum diberikan } \\
\text { Latihan ROM Pasif }\end{array}$ & 13,76 & 10,5 & 16,96 & $0-140$ \\
\hline $\begin{array}{l}\text { Nilai Rentang Gerak } \\
\text { Sendi sesudah diberikan } \\
\text { Latihan ROM Pasif }\end{array}$ & 15,9 & 10,5 & 11,88 & $0-143$ \\
\hline
\end{tabular}

Hasil penelitian menunjukkan rerata nilai rentang gerak sendi sebelum diberikan latihan ROM pasif pada responden adalah 13,755 dengan standar deviasi 16,96 , nilai terendah 0 dan nilai tertinggi 140. Setelah dilakukan latihan ROM pasif pada responden didapat nilai rerata adalah 15,9 dengan standar deviasi 11,88, nilai terendah 0 dan nilai tertinggi adalah 143.

Tabel 3.Perbedaan Rata-Rata Rentang Gerak Fleksi-Ekstensi Bahu Pada Pasien Pasca Stroke Sebelum dan Sesudah di Berikan Latihan ROM Pasif di RSUD M. Natsir Kota Solok

\begin{tabular}{lccccccc}
\hline \multicolumn{1}{c}{ Kelompok } & N & Mean & SD & Min-Max & P & Mean & SD \\
& & & & & & & \\
\hline Pre ekstensi bahu & 30 & 17,43 & 10,66 & $5-50$ & 0,000 & & \\
Post ekstensi bahu & 30 & 20,00 & 11,528 & $5-55$ & 0,000 & 2,567 & 1,851 \\
\hline Pre fleksi bahu & 30 & 24,60 & 27,645 & $5-140$ & 0,000 & & \\
Post fleksi bahu & 30 & 27,47 & 28,056 & $5-143$ & 0,000 & 2,867 & 2,255 \\
\end{tabular}

Hasil uji statistik didapatkan nilai 0,000 maka dapat disimpulkan ada perbedaan rentang gerak sendi yang signifikan antara pengukuran pre dan post. Rata-rata pre ekstensi bahu adalah 17,43 dengan standar deviasi 10,66. Rata-rata post ekstensi bahu adalah 20,00 dengan standar deviasi 11,528 . Terlihat nilai mean perbedaan antara pengukuran pre dan post fleksi bahu adalah 2,567 dengan Standar Deviasi 1,851. Hasil uji statistic didapatkan nilai 0,000 , ada perbedaan rentang gerak sendi yang signifikan antara pengukuran pre dan post.

Tabel 4. Perbedaan Rata-Rata Rentang Gerak Fleksi-Ekstensi Siku Pada Responden Pasca Stroke Sebelum dan Sesudah di Berikan Latihan ROM Pasif di RSUD M. Natsir Kota Solok ( $N=30)$

\begin{tabular}{cccccccc}
\hline Kelompok & N & Mean & SD & Min-Max & P & Mean & SD \\
\hline Pre ekstensi siku & 30 & 18,77 & 16,479 & $5-90$ & 0,000 & & \\
Post ekstensi siku & 30 & 21,43 & 16,888 & $7-93$ & 0,000 & 2,667 & 2,057 \\
\hline
\end{tabular}


Pada tabel, dapat dilihat rata-rata pre ekstensi siku adalah 18,77 dengan standar deviasi 16,479. Rata-rata post ekstensi siku adalah 21,43 dengan standar deviasi 16,888. Terlihat nilai mean perbedaan antara pengukuran pre dan post ekstensi siku adalah 2,667 dengan Standar Deviasi 2,057. Hasil uji statistic didapatkan nilai 0,000, ada perbedaan rentang gerak sendi yang signifikan antara pengukuran pre dan post.

Tabel 5. Perbedaan Rata-Rata Rentang Gerak Pergelangan Tangan Responden Pasca Stroke Sebelum dan Sesudah di Berikan Latihan ROM Pasif di RSUD M. Natsir Kota Solok $(\mathrm{N}=30)$

\begin{tabular}{|c|c|c|c|c|c|c|c|}
\hline Kelompok & $\mathbf{N}$ & Mean & SD & Min-Max & $\mathbf{P}$ & Mean & SD \\
\hline Pre fleksi pergelangan tangan & 30 & 13,97 & 8,830 & $4-45$ & 0,000 & & \\
\hline Post fleksi pergelangan tangan & 30 & 16,70 & 9,491 & $4-47$ & 0,000 & 2,733 & 2,703 \\
\hline $\begin{array}{l}\text { Pre ekstensi pergelangan } \\
\text { tangan }\end{array}$ & 30 & 13,10 & 8,976 & $3-50$ & 0,000 & & \\
\hline $\begin{array}{l}\text { Post ekstensi pergelangan } \\
\text { tangan }\end{array}$ & 30 & 15,47 & 9,992 & $5-55$ & 0,000 & 2,367 & 2,539 \\
\hline
\end{tabular}

Pada table, dapat dilihat bahwa rata-rata pre fleksi pergelangan tangan adalah 13,97 dengan standar deviasi 8,830. Rata-rata post fleksi pergelangan tangan adalah 16,70 dengan standar deviasi 9,491. Terlihat nilai mean perbedaan antara pengukuran pre dan post fleksi pergelangan tangan adalah 2,733 dengan Standar Deviasi 2,703. Hasil uji statistic didapatkan nilai 0,000 maka dapat disimpulkan ada perbedaan rentang gerak sendi yang signifikan antara pengukuran pre dan post. Rata-rata pre ekstensi pergelangan tangan adalah 13,10 dengan standar deviasi 8,976. Rata-rata post ekstensi pergelangan tangan adalah 15,47 dengan standar deviasi 9,992. Terlihat nilai mean perbedaan antara pengukuran pre dan post fleksi pergelangan tangan adalah 2,367 dengan Standar Deviasi 2,539. Hasil uji statistic didapatkan nilai 0,000 maka dapat disimpulkan ada perbedaan rentang gerak sendi yang signifikan antara pengukuran pre dan post.

\section{PEMBAHASAN}

Stroke adalah gangguan saraf yang menetap, yang diakibatkan oleh kerusakan pembuluh darah di otak, yang terjadi sekitar 24 jam atau lebih. Serangannya berlangsung selama 15-20 menit. Orang kerap menyebutnya sebagai serangan otak ${ }^{7}$. Stroke merupakan penyakit atau gangguan fungsional otak berupa kelumpuhan saraf (deficit neurologic) akibat terhambatnya aliran darah ke otak. WHO mendefinisikan stroke sebagai gejala defisit fungsi susunan saraf yang diakibatkan oleh penyakit pembuluh darah otak dan bukan oleh yang lain 5 .

Hasil penelitian menunjukkan bahwa ada perbedaan latihan ROM Pasif terhadap rentang gerak sendi pasien. beberapa responden tidak mengalamii peningkatan derajat lingkup gerak sendi. Hal ini dipengaruhi oleh usia, dukungan keluarga dan motivasi pasien sendiri, semakin bertambahnya usia, masalah yang sering dialami berupa gangguan atau perubahan fungsi fisik maupun psikologis. Hal ini ditandai dengan adanya perubahan pada 
sistem muskoloskletal dimana terjadi penurunan fungsi dan masa dari sel, otot yang kendur, berkurang nya energi, sering merasa lelah, gerakan tangan yang berkurang serta persendian yang mulai rapuh.Sehingga hal ini dapat mempengaruhi kemampuan responden dalam melakukan latihan ROM serta hanya sebagian kecil perubahan yang bisa terjadi pada rentang gerak sendinya.

Pasien stroke perlu penanganan yang lebih baik untuk mencegah kecacatan fisik dan mental. Pasien stroke akan dapat sembuh sempurna dan ada juga yang mengalami kelemahan fisik seperti hemiparese. Salah satu program rehabilitasi yang dapat diberikan yaitu mobilisasi persendian dengan latihan range of motion.Sendi dan otot harus digerakkan dengan maksimum dan dilakukan secara teratur, komplikasi yang sering terjadi adalah abnormalitas tonus, kontraktur.Atropi otot karna kurang aktifitas, kotraktur merupakan salah satu penyebab terjadinya penurunan kemampuan pasien melakukan rentang gerak sendi.

Salah satu bentuk rehabilitasi awal pada penderita stroke adalah dengan memberikan mobilisasi berupa ROM (Range of Motion) baik pasif maupun aktif.Latihan Range of Motion (ROM) merupakan salah satu bentuk latihan dalam proses rehabilitasi yang dinilai masih cukup efektif untuk mencegah terjadinya kecacatan pada pasien dengan stroke ${ }^{8}$. Latihan ini adalah salah satu bentuk intervensi fundamental perawat yang dapat dilakukan dalam bentuk terapi terapeutik bagi pasien dan dalam upaya pencegahan terjadinya kondisi cacat permanen pada pasien pasca perawatan di rumah sakit sehingga dapat menurunkan tingkat ketergantungan pasien pada keluarga. Sebaiknya latihan pada pasien stroke dilakukan beberapa kali dalam sehari untuk mencegah komplikasi. Semakin dini proses rehabilitasi dimulai maka kemungkinan pasien mengalami defisit kemampuan akan semakin kecil ${ }^{1}$.

Penelitian ini menunjukkan kesesuaian dengan teori latihan ROM Pasif yaitu salah satu tujuan dari latihan tersebut adalah mempertahankan rentang gerak sendi atau memelihara kekuatan otot ${ }^{11}$. Hal ini sejalan dengan penelitian yang dilakukan oleh Anita (2018). mengatakan bahwa rentang gerak sendi pasien pasca stroke sebelum di lakukan latihan range of motion menunjukkan bahwa luas derajat rentang gerak sendi ekstremitas atas seperti sendi peluru, engsel dan sendi kandiloid mengalami keterbatasan. Namun sesudah dilakukan latihan range of motion menunjukkan bahwa luas derajat rentang gerak sendi mengalami peningkatan yang membuktikan bahwa ada pengaruh latihan range of motion terhadap rentang gerak sendi ekstremitas atas pada pasien stroke ${ }^{10}$.

Dalam penelitian Pongantung H,Sampe Anita, (2018) mengatakan bahwa penderita stroke harus di mobilisasi sedini mungkin. Salah satu mobilisasi dini yang dapat segera dilakukan adalah pemberian latihan range of motion yang bertujuan untuk meningkatkan kemandirian pasien pasca stroke ${ }^{10}$. Penelitian Kusuma dan sara, (2020) mendapatkan bahwa latihan ROM sedini mungkin secara berkelanjutan terbukti dapat meningkatkan kekuatan otot pada pasien stroke. Pemberian latihan ROM dengandurasi waktu 15-35 menit 
dilakukan dua kali sehari setiap pagi dan sore minimal pelaksanaan 4 minggu $^{12}$.Saran dalam melakukan intervensi keperawatan padapasien stroke dapat dilakukan secara menyeluruh meliputi bio, psiko, spiritual. Tindakan keperawatan yang mencakup biologis dalam kasus stroke seperti melakukan latihan ROM,yang mencakup psikologis dengan teknik relaksasi berupa latihan pernapasan atau mendengarkan musik, dan yangmencakup spiritual dengan berdoa. Jadi untuk meningkatkan kekuatan otot secara optimal dapat dilakukan dengan mengkombinasikan latihan yang dilakukan sedini mungkin.Relaksasi dan berdoa dilakukan sebelum latihan ROM dimulai agar pasien merasa tenang ${ }^{12}$.

Dari hasil penelitian, diketahui beberapa responden tidak mengalamii peningkatan derajat lingkup gerak sendi. Hal ini dipengaruhi oleh usia, dukungan keluarga dan motivasi pasien sendiri. Menurut Indah sari (2015) semakin bertambahnya usia, masalah yang sering dialami berupa gangguan atau perubahan fungsi fisik maupun psikologis. Hal ini ditandai dengan adanya perubahan pada sistem muskoloskletal dimana terjadi penurunan fungsi dan masa dari sel, otot yang kendur, berkurang nya energi, sering merasa lelah, gerakan tangan yang berkurang serta persendian yang mulai rapuh.Sehingga hal ini dapat mempengaruhi kemampuan responden dalam melakukan latihan ROM serta hanya sebagian kecil perubahan yang bisa terjadi pada rentang gerak sendinya ${ }^{13}$. Hasil penelitian ini juga di dukung oleh penelitian yang dilakukan oleh Yudha (2014) tentang Pengaruh Range of Motion terhadap kekuatan otot pasien pasca preawatan stroke yang mendapatkan hasil bahwa latihan ROM memiliki pengaruh terhadap rentang gerak sendi pasien ${ }^{14}$. Hasil penelitian yang dilakukan oleh Bakara, D. M., \& Warsito, (2016) menunjukkan adanya perbedaan sebelum dan sesudah dilakukan range of motion ${ }^{9}$.

Penelitian Kusuma, (2020) menyatakan bahwa latihan Range of Motion dengan durasi 15-35 menit dilakukan dua kali sehari pagi dan sore selama 4 minggu awali dengan teknik relaksasi berupa latihan pernafasan, atau mendengarkan music serta spiritual dengan berdoa. Dengan melakukan tindakan keperawatan dengan kombinasi ini dapat meningkatkan kekuatan otot pasien stroke ${ }^{12}$. Berdasarkan hasil penelitian Ratnasari, S. (2020) didapatkan hasil akhir bahwa mengajarkan latihan rentang gerak dapat meningkatkan kekuatan otot pasien dan dapat membantu pasien dalam melakukan aktivitas sehari-hari pada pasien stroke non hemoragik untuk mengatasi masalah gangguan mobiltas fisik $^{15}$. Hasil penelitian Rahayu (2014) menunjukkan ada pengaruh pemberian latihan range of motion terhadap kemampuan motorik pada pasien post stroke. Penelitian ini merekomendasikan perlunya penelitian lebih lanjut dan penggunaan latihan ini sebagai salah satu intervensi mandiri perawat dalam asuhan keperawatan pasien stroke ${ }^{16}$.

Peningkatan rentang gerak sendi dapat mengaktifkan gerak volunter yaitu gerak volunter terjadi adanya transferimpuls elektrik dan girus presentralis ke korda spinalis melalui nurotransmiter yang mencapai otot dan menstimulasi otot sehingga menyebabkan 
pergerakan ${ }^{5}$. Untuk menimbulkan gerakan disadari kearah normal, pertama kali yang dilakukan adalah memperbaiki tonus otot maupun reflex tendon kearah normal yaitu dengan cara memberikan stimulus terhadap otot maupun proprioceptor di persendian yaitu melalui approksimasi. Perawat memegang peran penting disini yaitu melakukan stimulus dan ransangan melalui gerakan / latihan ROM pasif terlebih dahulu kemudian secara bertahan melakukan ROM aktif. Selain dari latihan secara terstruktur kegiatan ini melibatkan keluarga dan memotivasi pasien serta keluarga untuk melakukan latihan secara teratur.

\section{SIMPULAN DAN SARAN}

Terdapat pengaruh yang mermakna bahwa ROM pasif yang dilakukan pada pasien stroke meningkatkan rentang gerak sendi, dimana selama gerakan ROM pasif yang dilakukan pada pasien sebanyak dua kali sehari selama enam hari dilakukan secara teratur meningkatkan aliran darah sendi yang mengalami paralisis sehingga terjadi peningkatan penambahan rentang sendi abduksi-adduksi pada ekstremitas atas hanya pada sendi besar. Sehingga ROM pasif dapat dilakukan sebagai alternative dalam meningkatkan rentang gerak sendi pasien stroke yang mengalami paralisis.

Saran untuk perawat atau tim yang terlibat dalam penanganan pasien stroke yang mengalami kelemahan ekstremitas untuk melakukan larihan ROM secara teratur dengan melibatkan keluarga, terutama ruang rawat neorologi RSUD M.Natsir serta lebih mengoptimalkan dalam memberikan Latihan ROM Pasif Pada Pasien Stroke untuk meningkatkan Rentang Gerak Sendi pada Pasien Stroke.

\section{DAFTAR PUSTAKA}

1. Brunner, \& Suddarth. Keperawatan Medikal-Bedah. EGC.2013

2. Widyanto, F. C., \& Triwibowo, C. Trend Disease Trend Penyakit Saat Ini. CV.Trans Info Media.2013.

3. Alan dkk. Heart Desiase and Stroke Statistics. Volume 129, Issue 3, 21 January 2014, Pages e28- e292. https://doi.org/10.1161/01.cir.0000441139.02102.80

4. Balitbangkes. Riskesdas. https://labmandat.litbang.kemkes.go.id/riset-badanlitbangkes/menu-riskesnas/menu-riskesdas/426-rkd-2018

5. Potter, \& P. Buku Ajar Fundamental Keperawatan Konsep, Proses, dan Praktik. EGC. 2015

6. Dharma, K. K. Pemberdayaan Keluarga Mengoptimalkan Kualitas Hidup Pasien Pasca Stroke. CV.Budi Utama.2018

7. Sutrisno, A. Stroke? Sebaiknya Anda Tahu Sebelum Anda Terserang Stroke. Gramedia Pustaka Utama.2017 
8. Yueniwati, Y. Deteksi Dini Stroke Iskemia Dengan Pemeriksaan Ultrasonografi Vaskular dan ariasi Genetika. UB Press.2015.

9. Bakara, D. M., \& Warsito, S. Latihan Range Of Motion (ROM) Pasif terhadap Rentang sendi Pasien pasca Stroke. Idea Nursing Journal, VII (2).2016 http://jurnal.unsyiah.ac.id//NJ/article/view/6450/5289

10. Anita, F., Henny, P., Ada, P. veni, \& Hingkam, V. Pengaruh Latihan Range Of Motion Terhadap Rentang Gerak Sendi Ekstremitas Atas Pada Pasien Pasca Stroke Di Makassar. Journal of Islamic Nursing, 2018. 3(1).http://download.garuda.ristekdikti.go.id/article.

11. Marlina. Pengaruh Latihan ROM Terhadap Peningkatan Kekuatan Otot pada Pasien Stroke Iskemik di RSUDZA Banda Aceh. Idea Nursing Journal Vol. III No. 1.2016 http://jurnal.unsyiah.ac.id/INJ/article/view/6407

12. Kusuma, A. S., \& Sara, O. Penerapan Prosedur Latihan Range Of Motion (ROM) Pasif Sedini Mungkin pada Pasien Stroke Non Hemoragik (SNH). Syntax Literate; Jurnal Ilmiah Indonesia, 5(10), 1015-1021.2020 http://www.jurnal.syntaxliterate.co.id/index.php/syntax-literate/article/view/1706

13. Indahsari, N., \& Dkk. Hubungan Perubahan Fungsi Fisik Terhadap Kebutuhan Aktivitas Hidup Sehari-Hari (AHS) Pada Lansia Dengan Stroke (Studi Pada Unit Rehabilitasi Sosial Kota Semarang). Jurnal Keperawatan Komunitas . Volume 1, No. 1. 2015 https://jurnal.unimus.ac.id/index.php/JKK/article/view/922

14. Yudha, F \& Gustop, A. Pengaruh Range Of Motion (ROM) Terhadap Kekuatan Otot Pasien Pasca Perawatan Stroke. Jurnal Keperawatan, Volume X, No. 2. 2014.

15. Ratnasari, S. Asuhan Keperawatan Pada Pasien Stroke Non Hemoragik Dengan Masalah Keperawatan Gangguan Mobilitas Fisik (Doctoral dissertation, Universitas Muhammadiyah Ponorogo).2020 http://eprints.umpo.ac.id/6185/

16. Rahayu, K. I. N. (2016). Pengaruh pemberian latihan range of motion (rom) terhadap kemampuan motorik pada pasien post stroke di rsud gambiran. Jurnal keperawatan, $6(2)$. 